\title{
Lipomatous Medulloblastoma: A Case Report
}

\author{
Ibrahima Berete ${ }^{*}$, Alpha Boubacar Bah ${ }^{1}$, Seylan Diawara ${ }^{1}$, Hammas Nawal2, \\ Mohammed Benzagmout ${ }^{3}$, Khalid Chakour ${ }^{3}$, Mohammed Faiz Chaoui ${ }^{3}$ \\ ${ }^{1}$ Department of Neurosurgery, University Hospital Donka, Conakry, Guinea \\ ${ }^{2}$ Department of Pathology, University Hospital Hassan II, Fez, Morocco \\ ${ }^{3}$ Department of Neurosurgery, University Hospital Hassan II, Fez, Morocco \\ Email: ^iberete902@icloud.com
}

How to cite this paper: Berete, I., Bah, A.B., Diawara, S., Nawal, H., Benzagmout, M., Chakour, K. and Chaoui, M.F. (2019) Lipomatous Medulloblastoma: A Case Report. Open Journal of Modern Neurosurgery, 9, 452-456.

https://doi.org/10.4236/ojmn.2019.94043

Received: March 27, 2019

Accepted: October 22, 2019

Published: October 25, 2019

Copyright $\odot 2019$ by author(s) and Scientific Research Publishing Inc. This work is licensed under the Creative Commons Attribution International License (CC BY 4.0).

http://creativecommons.org/licenses/by/4.0/ Open Access

\begin{abstract}
Lipomatous medulloblastoma is not a separate entity but apparently distinct variant of medulloblastoma. Since the first case report in 1978 by Bechtel et al. [1], few cases have been published. We report an additional case of a 52-year-old right-handed man presented to the emergency department with evaluation of progressive severe intracranial hypertension and ataxia. His past medical history was unremarkable. His physical examination showed cerebellar syndromes. He underwent magnetic resonance imaging (MRI) which revealed a unique mass in the posterior fossa, lying within a cerebellar hemisphere. The patient underwent a suboccipital craniotomy for with a complete resection and samples were sent for histologic examination, showing closely packed, and round to oval cells. The nuclei had an irregular shape with clumps of heterochromatin. Lipid accumulation was a prominent feature of neoplastic cells. Postoperatively the patient did not receive fractionated radiotherapy. He is alive without deficit and with no evidence of recurrence on neuroimaging.
\end{abstract}

\section{Keywords}

Medulloblastoma, Lipomatous, Liponeurocytoma, Posterior Fossa, Tumor, Suboccipital Craniotomy

\section{Introduction}

Lipomatous medulloblastoma is not an entity but apparently distinct variant of medulloblastoma. The first case report was 1978 by Bechtel et al. [1]. It was first included in the 2000 World Health Organisation (WHO) 3rd edition of Central Nervous System (CNS) tumors' classification as a separate grade I entity labelled as cerebellar liponeurocytoma, but the histo-pathological origin of this tumor is 
still controversial [2]. We report an additional case in an adult who presented with a posterior fossa tumor.

\section{Case Report}

A 52-year-old right-handed man presented to the emergency department with evaluation of progressive severe headaches, nausea/vomiting, and ataxia. The patient's symptoms began approximately 4 months ago. One week prior to this visit he began to notice ataxia; he denied any change in his voice or swallowing difficulty. His past medical history was unremarkable. His physical examination showed a Glasgow coma scale of 15, and pupils' examination was normal. The neurologic examination found a cerebellar syndrome. The clinical picture strongly suggested an abnormality in the posterior fossa. He underwent a magnetic resonance imaging (MRI) that showed a mass in the posterior fossa lying within the cerebellar hemisphere and enhancing irregularly with contrast, along with obstructive hydrocephalus, significant mass effect and tonsillar herniation (Figure 1). The patient underwent a suboccipital craniotomy to resect this cerebellar lesion and samples were sent for histopathologic examination showing closely packed, round to oval cells. The nuclei had an irregular shape with clumps of heterochromatin. Lipid accumulation was a prominent feature of neoplastic cells (Figure 2). Postoperatively the patient did not receive fractionated radiotherapy. He is alive without deficit and no evidence of disease on neuroimaging at 5 years follow-up.

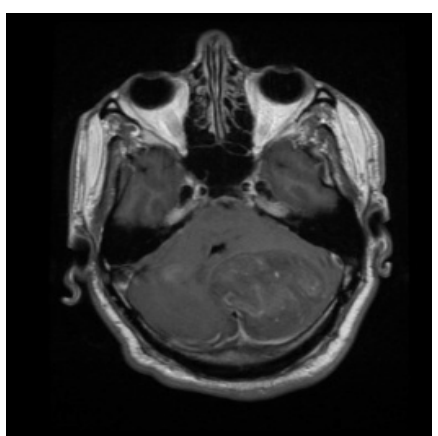

(a)

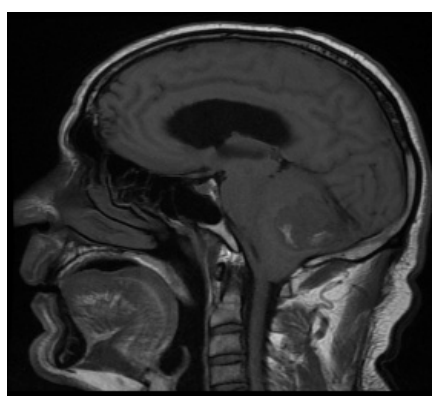

(c)

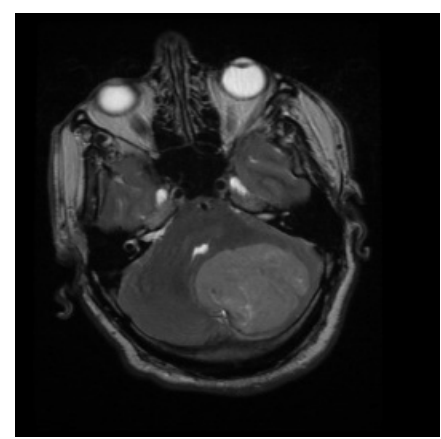

(b)

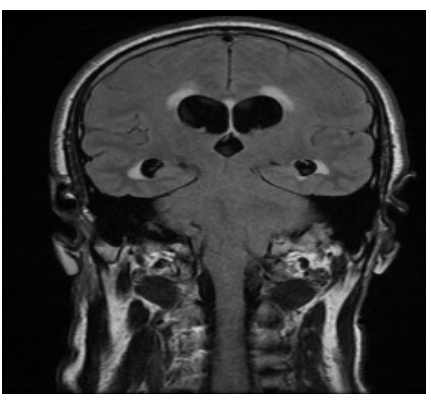

(d)

Figure 1. MRI of the brain (a) Axial T1; (b) Axial T1; (c) Sagittal T1; (d) Coronal T1 show a mass in the posterior fossa lying within the cerebellar hemisphere and moderately enhancing along with obstructive hydrocephalus significant mass effect and tonsillar herniation. 


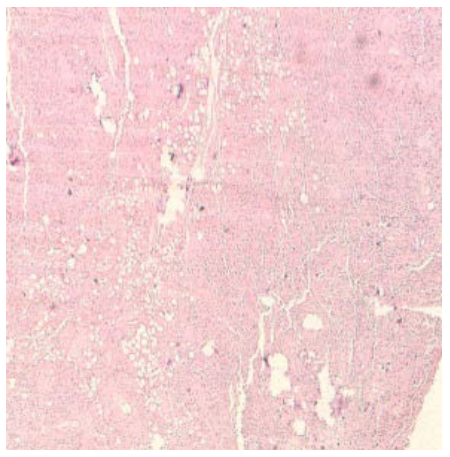

(a)

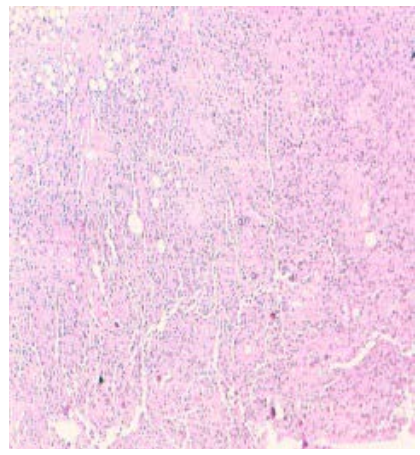

(b)

Figure 2. Photomicrograph of light microscopic findings on hematoxylin and eosin. (a) Low power view of the classical medulloblastoma shows typical small blue cell tumor with a high nuclear to cytoplasmic ratio; (b) High power view shows prominent areas of lipidization.

\section{Discussion}

Medulloblastoma is the most common solid malignancy seen in children. It rarely occurs in adults [3] [4]. Medulloblastomas represent $1 \%$ of all adult primary central nervous system (CNS) tumors. It is well known to have multiple histopathological variations, including tumors displaying predominantly neuronal, glial, and/or myoid differentiation. Overall, medulloblastomas in adults and children have a similar clinical course and prognosis with 5-year actuarial survival rates of approximately $50 \%$ with aggressive multidisciplinary management [5] [6] [7]. The lipomatous' variant was first reported in 1978 [1]. Since, few cases have been reported [6] [8]. It is not yet recognized as a separate pathologic entity in the most recent World Health Organization (WHO) classification scheme [9]. Although WHO criteria have labeled this variant as a "cerebellar liponeurocytoma", the histopathological origin of this tumor is still controversial. Therefore, because of the glial versus neuronal origin conflict with this tumor, we have decided to label it as a lipomatous medulloblastoma. Most reported cases have occurred in middle-aged adults (median age, 50; range, 30 - 66). Gender predilection appears to be evenly distributed (Sex-ratio 2F/3H) [5]. All but one tumor arose in the cerebellum, with the exception being a supratentorial tumor located in periventricular white matter [8]. It has been suggested that this tumor variant may be more likely to appear hyperintense on T1-weighted MRI [4]. In our patient it was not the case, and this imaging characteristic should be considered unreliable. The pathologic findings are typical for medulloblastoma, positive immunohistochemical staining for neuron-specific enolase (NSE) and glial fibrillary acidic protein (GFAP) [7]. The only differentiating factor was the abundancy of intracytoplasmic lipid accumulation. Because of the presence of adipocytes, additional terms that have been proposed for these tumors including neurolipocytoma and medullocytoma [10]. The lipomatous variant of medulloblastoma carries a very different prognosis than the classical medulloblastoma [6]. In the absence of postoperative complications, high long-term survival ap- 
pears to be the rule rather than the exception for these patients. Only 6 cases of postoperative radiotherapy were reported [2] [3]. Our study is concordant with the literature in their adult presentation and posterior fossa predilection. The fact that our patient has no evidence of disease recurrence at follow-up after complete resection confirms the uniquely benign prognosis of this distinct medulloblastoma variant.

\section{Conclusion}

The present study reported a case of lipomatous medulloblastoma that was successfully treated by total resection. A review of the literature showed that distinct variant of medulloblastoma is rare, may locate supratentorially or infratentorially and appear to occur in adults. The optimal treatment strategy appears to be a total resection and close follow-up, with a uniquely favorable prognosis. However, due to the rarity of the tumor and limited data available, long-term follow-up is required.

\section{Patient Consent}

An informed written consent was obtained from the patient.

\section{Conflicts of Interest}

The authors declare no conflicts of interest regarding the publication of this paper.

\section{References}

[1] Bechtel, J.T., Paon, J.M. and Takei, Y. (1978) Mixed Mesenchymal and Neuroectodermal Tumour of the Cerebellum. Acta Neuropathologica, 41, 261-263.

https://doi.org/10.1007/BF00690447

[2] Pasquale, G., Maria, B.A., Vania, P., Gastone, P., et al. (2009) Cerebellar Liponeurocytoma: An Updated Follow-Up of a Case Presenting Histopathological and Clinically Aggressive Features. Neurology India, 57, 194-196. https://doi.org/10.4103/0028-3886.51294

[3] Davis, D.G., Wilson, D., Schmitz, M. and Markesbury, W.R. (1993) Lipidized Medulloblastoma in Adults. Human Pathology, 24, 990-995.

https://doi.org/10.1016/0046-8177(93)90113-U

[4] Ellison, D.W., Zygment, S.C. and Weller, R.O. (1993) Neurocytoma/Lipoma (Neurolipocytoma) of the Cerebellum. Neuropathology and Applied Neurobiology, 19, 95-98. https://doi.org/10.1111/j.1365-2990.1993.tb00410.x

[5] Giangaspero, F., Cenacchi, G., Roncaroli, F., et al. (1996) Medullocytoma (Lipidized Medulloblastoma): A Cerebellar Neoplasm of Adults with Favorable Prognosis. The American Journal of Surgical Pathology, 20, 656-664. https://doi.org/10.1097/00000478-199606000-00002

[6] Elshihabi, S., Husain, M. and Linskey, M. (2003) Lipomatous Medulloblastoma: A Rare Adult Tumor Variant with a Uniquely Favorable Prognosis. Surgical Neurology, 60, 566-570. https://doi.org/10.1016/S0090-3019(03)00192-7

[7] Kleihues, P. and Giangaspero, F. (1997) Lipomatous Medulloblastoma. In: Kleihues, 
P. and Cavenee, W.K., Eds., Pathology and Genetics of Tumours of the Nervous System, Oxford University Press, Oxford, 107.

[8] Orlandi, A., Marino, B., Brunori, M., Greco, R. and Spagnoli, L.G. (1997) Lipomatous Medulloblastoma. Clinical Neuropathology, 16, 175-179.

[9] Soylemezoglu, F., Soffer, D., Onol, B., Schwechheimer, K. and Kleihues, P. (1996) Lipomatous Medulloblastoma in Adult: A Distinct Clinicopathological Entity. The American Journal of Surgical Pathology, 20, 413-418. https://doi.org/10.1097/00000478-199604000-00003

[10] Owler, B.K., Makeham, J.M., Shingde, M. and Besser, M. (2005) Cerebelar Liponeurocytoma. Journal of Clinical Neuroscience, 12, 326-329.

https://doi.org/10.1016/j.jocn.2004.05.017 